\title{
The heat transfer coefficient determination with the use of the Beck-Trefftz method in flow boiling in a minichannel
}

\author{
Kinga Strąk $^{1}$, Beata Maciejewska ${ }^{2 *}$, Magdalena Piasecka ${ }^{3}$ \\ ${ }^{1,3}$ Faculty of Mechatronics and Mechanical Engineering \\ ${ }^{2}$ Faculty of Management and Computer Modelling \\ Kielce University of Technology, Al. 1000-lecia P.P. 7, 25-314 Kielce, Poland
}

\begin{abstract}
In this paper, the solution of the two-dimensional inverse heat transfer problem with the use of the Beck method coupled with the Trefftz method is proposed. This method was applied for solving an inverse heat conduction problem. The aim of the calculation was to determine the boiling heat transfer coefficient on the basis of temperature measurements taken by infrared thermography. The experimental data of flow boiling heat transfer in a single vertical minichannel of $1.7 \mathrm{~mm}$ depth, heated asymmetrically, were used in calculations. The heating element for two refrigerants (FC-72 and HFE-7100, 3M) flowing in the minichannel was the plate enhanced on the side contacting with the fluid. The analysis of the results was performed on the basis of experimental series obtained for the same heat flux and two different mass flow velocities. The results were presented as infrared thermographs, heated wall temperature and heat transfer coefficient as a function of the distance from the minichannel inlet. The results was discussed for the subcooled and saturated boiling regions separately.
\end{abstract}

\section{Introduction}

Boiling is an effective heat transfer process, which due to the phase change provides high heat transfer capacity. Flow boiling heat transfer is used in many applications utilizing the heat-removal processes. Variations in the process intensity may be, however, a limitation to the efficiency of boiling heat transfer, characterized by heat transfer coefficient values and can be estimated due to the heat transfer coefficient values.

Inverse heat conduction problems [1, 2], such as heat transfer coefficient identification, are solved with a number of numerical methods. One of these methods is the Beck method $[3,4]$, which introduces sensitivity coefficients as derivatives of the measured quantity with respect to the identified quantity and transforms an inverse problem into several direct problems. In this paper, the Trefftz method [5] was used to solve direct problems by approximating the unknown solution to a differential equation with a linear combination of functions strictly satisfying the governing differential equation. The Trefftz method was explored in more detail in [6-14].

The presented method is used to solve the heat transfer problem in the flow in channels. Similar issues are discussed in articles [15-22].

\section{Experimental setup and methodology}

The major elements of the experimental stand are presented in Fig. 1a. The essential part of the stand is the test section (Fig. 1b) with a single rectangular minichannel, $1.7 \mathrm{~mm}$ in depth, $16 \mathrm{~mm}$ in width and $180 \mathrm{~mm}$ in length. The heated plate (12) made of Haynes-230 alloy, $0.45 \mathrm{~mm}$ thick, was enhanced by vibration-assisted laser surface on the side contacting refrigerant.

It was possible to measure temperature on the outer side of the plate due to infrared camera (Fig. 1,2). The E60 FLIR infrared camera (2) had an accuracy of $\pm 1{ }^{\circ} \mathrm{C}$ or $\pm 1 \%$ in the temperature range $0 \div 120{ }^{\circ} \mathrm{C}$ [23]. This smooth plate surface was coated with a black paint of known emissivity (of 0.83) [24]. The enhanced surface of the heated plate was observed through a glass panel (14). The flow patterns were recorded using a quick shot camera (3). K-type thermocouples (17) and pressure sensors measured temperature and pressure at the inlet and outlet of the minichannel, respectively.

During experiment, there was a laminar flow of refrigerant along a minichannel and a gradual increase in the electric power supplied to the plate followed by an increase in the heat flux transferred to the fluid. Experimental parameters for several settings of the heat flux supplied to the heated plate during subcooled and saturated boiling region were collected. The experimental parameters are presented in Table 1 and physical properties of refrigerants in Table 2 .

The results were analysed for:

- two refrigerants, FC-72 and HFE-7100 (3M), used as working fluids in the flow loop,

- two mass flow velocities: $Q_{m}=12 \cdot 10^{-3} \mathrm{~kg} \cdot \mathrm{s}^{-1}$ and $Q_{m}=18 \cdot 10^{-3} \mathrm{~kg} \cdot \mathrm{s}^{-1}$,

Corresponding author:beatam@tu.kielce.pl 
- four heat fluxes: $40 \mathrm{~kW} \cdot \mathrm{m}^{-2}, 52 \mathrm{~kW} \cdot \mathrm{m}^{-2}, 59 \mathrm{~kW} \cdot \mathrm{m}^{-2}$ and $68 \mathrm{~kW} \cdot \mathrm{m}^{-2}$ set at the subcooled boiling region,

- two heat fluxes: $120 \mathrm{~kW} \cdot \mathrm{m}^{-2}$ and $125 \mathrm{~kW} \cdot \mathrm{m}^{-2}$, set at the saturated boiling region.

a)

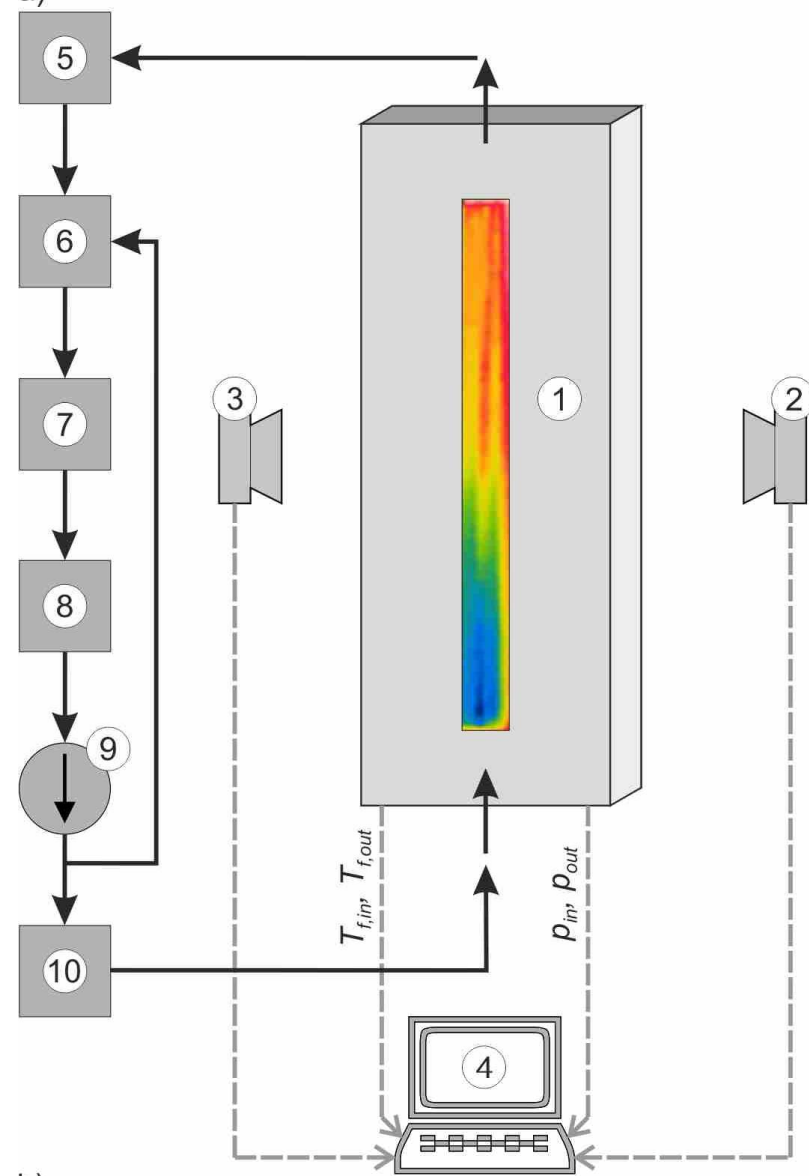

b)

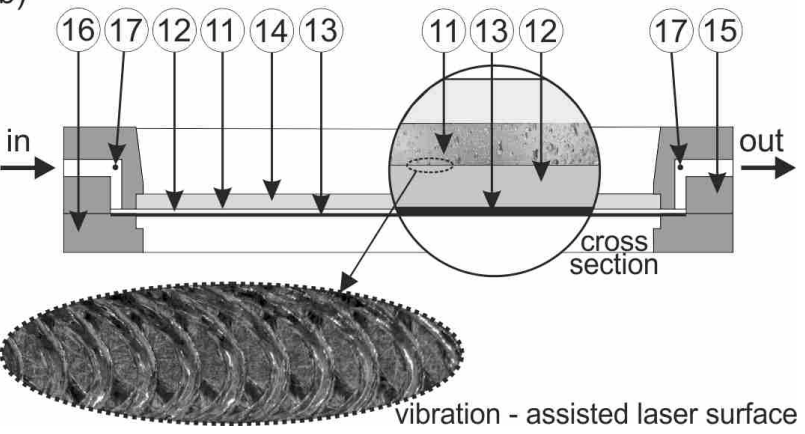

Fig. 1. a) The schematic diagram of the main elements of the experimental stand: 1-test section, 2-infrared camera, 3-quick shot camera, 4-data acquisition station with pc computer, 5-tube-type heat exchanger, 6-compensating tank/pressure regulator, 7-deaerator, 8-filter, 9- gear pump, 10-mass flowmeter; b) the schematic diagram of the test section: 11- minichannel, 12-heated plate, 13-black paint layer, 14-glass panel, 15-channel body, 16-front cover, 17-thermocouple.

\section{Heat transfer determination}

\subsection{Main assumptions}

It was assumed that the heat flow in the minichannel was stationary and two-dimensional. The variation in temperature along the channel width was neglected.

Local values of the heat transfer coefficient were calculated from Newton's law:

$$
\alpha(x)=\frac{q(x)}{T(x, \delta)-T_{f}(x)}
$$

where: $x$ - the flow direction, $y$ - the direction perpendicular to the flow direction, related to the thickness of the plate, $q$ - density of the heat flux transferred from the plate to the fluid, $T$ - plate temperature, $\delta$-thickness of the plate, $T_{f}$ - temperature of the fluid, in the subcooled boiling region it equals to $T_{l}(x)$ and in the saturated nucleate boiling region it equals to $T_{s a t}(x), T_{l}(x)$ - liquid temperature calculated from the assumption of the linear distribution of the liquid temperature along the channel and $T_{\text {sat }}$ - saturation temperature determined on the basis of the linear distribution of the fluid pressure along the channel. The heat flux density $q$ was calculated from Fourier's law.

Table 1 Experimental parameters of experimental series for the subcooled and saturated boiling regions.

\begin{tabular}{|c|c|c|c|c|}
\hline $\begin{array}{l}\text { Set of } \\
\text { heat } \\
\text { flux } \\
\text { (No.) }\end{array}$ & $\begin{array}{c}\text { Range of } \\
\text { mass flux } \\
G \\
\left(\mathrm{~kg} \mathrm{~m}^{-2} \mathrm{~s}^{-1}\right)\end{array}$ & $\begin{array}{c}\text { Range } \\
\text { of inlet } \\
\text { pressure } \\
p_{\text {in }} \\
(\mathrm{kPa})\end{array}$ & $\begin{array}{c}\text { Range of } \\
\text { inlet liquid } \\
\text { subcooling } \\
\Delta T_{s u b} \\
\text { (K) }\end{array}$ & $\begin{array}{c}\text { Heat } \\
\text { flux } \\
\text { density } \\
q_{w} \\
\left(\mathrm{kWm}^{-2}\right)\end{array}$ \\
\hline \multicolumn{5}{|c|}{ Subcooled boiling region } \\
\hline 1 & \multirow{4}{*}{$423-650$} & \multirow{4}{*}{$111-210$} & \multirow{4}{*}{$43-70$} & 40 \\
\hline 2 & & & & 52 \\
\hline 3 & & & & 59 \\
\hline 4 & & & & 68 \\
\hline $\begin{array}{l}\text { Set of } \\
\text { heat } \\
\text { flux } \\
\text { (No.) }\end{array}$ & $\begin{array}{c}\text { Range of } \\
\text { mass flux } \\
G \\
\left(\mathrm{~kg} \mathrm{~m}^{-2} \mathrm{~s}^{-1}\right)\end{array}$ & $\begin{array}{c}\text { Range } \\
\text { of inlet } \\
\text { pressure } \\
p_{\text {in }} \\
(\mathrm{kPa}) \\
\end{array}$ & $\begin{array}{c}\text { Range of } \\
\text { inlet liquid } \\
\text { subcooling } \\
\Delta T_{\text {sub }} \\
(\mathrm{K})\end{array}$ & $\begin{array}{c}\text { Heat } \\
\text { flux } \\
\text { density } \\
q_{w} \\
\left(\mathrm{kWm}^{-2}\right)\end{array}$ \\
\hline \multicolumn{5}{|c|}{ Saturated boiling region } \\
\hline 1 & \multirow{2}{*}{$440-638$} & \multirow{2}{*}{$147-229$} & \multirow{2}{*}{$44-66$} & 120 \\
\hline 2 & & & & 125 \\
\hline
\end{tabular}

Table 2 The basic thermal and flow properties of and $\mathrm{Novec}^{\mathrm{TM}}$ HFE-7100 and Fluorinert FC-72 [25].

\begin{tabular}{|l|c|c|c|}
\hline \multicolumn{2}{|c|}{ Properties } & \multicolumn{2}{c|}{ Fluids } \\
\hline & Unit & $\begin{array}{c}\text { HFE- } \\
\mathbf{7 1 0 0}\end{array}$ & FC-72 \\
\hline Boiling point & $\mathrm{K}$ & 334 & 329 \\
\hline Molecular weight & $\mathrm{kg} \cdot \mathrm{mol}^{-1}$ & 0.250 & 0.338 \\
\hline Vapor pressure & $\mathrm{Pa}$ & $27 \cdot 10^{3}$ & $30 \cdot 10^{3}$ \\
\hline Heat of vaporization & $\mathrm{J} \cdot \mathrm{kg}^{-1}$ & $112 \cdot 10^{3}$ & $88 \cdot 10^{3}$ \\
\hline Liquid density & $\mathrm{kg} \cdot \mathrm{m}^{-3}$ & 1510 & 1680 \\
\hline $\begin{array}{l}\text { Coefficient of } \\
\text { expansion }\end{array}$ & $\mathrm{K}^{-1}$ & 0.0018 & 0.0016 \\
\hline Kinematic viscosity & $\mathrm{m}^{2} \cdot \mathrm{s}^{-1}$ & $0.38 \cdot 10^{3}$ & $0.38 \cdot 10^{3}$ \\
\hline Specific heat & $\mathrm{J} \cdot \mathrm{kg}^{-1} \cdot \mathrm{K}^{-1}$ & 1183 & 1100 \\
\hline Thermal conductivity & $\mathrm{W} \cdot \mathrm{m}^{-1} \cdot \mathrm{K}^{-1}$ & 0.069 & 0.057 \\
\hline Surface tension & $\mathrm{N} \cdot \mathrm{m}^{-1}$ & 0.0136 & 0.01 \\
\hline
\end{tabular}




\subsection{Methodology of calculations, boundary conditions}

The plate temperature $T$ was determined by solving the inverse heat conduction problem in the heated plate:

$$
\frac{\partial^{2} T}{\partial x^{2}}+\frac{\partial^{2} T}{\partial y^{2}}=-\frac{I \Delta U}{A \delta \lambda}=-\frac{q_{w}}{\delta \lambda} \text { for }(x, y) \in \Omega
$$

where $\Omega=\left\{(x, y) \in R^{2}: x_{1}<x<x_{P}, \quad 0<y<\delta\right\}$, and the boundary conditions (see Fig. 2):

$$
\begin{gathered}
T\left(x_{1}, y\right)=T_{1} \text { for } 0<y<\delta \\
T\left(x_{P}, y\right)=T_{P} \text { for } 0<y<\delta \\
\frac{\partial T}{\partial y}(0, y)=0 \text { for } x_{1}<x<x_{P} \\
T\left(x_{p}, 0\right)=T_{p} \text { for } p=1,2, \ldots P
\end{gathered}
$$

where: $I$ - current supplied to the heated plate, $\Delta U-$ drop in voltage along the length of the plate, $A$ - surface area of the heated plate in contact with the fluid, $\delta$ - thickness of the heated plate, $q_{w}$ - heat flux density, $x_{1}$ - location of the first measurement point at the boundary $y=0, x_{p}-$ location of the last measurement point, $P$ - number of measurements, $T_{p}$ - measured temperature of the heated plate, $\lambda$ - thermal conductivity of the heated plate.

The inverse problem (Eqs. 2-6) was solved using the Beck method.

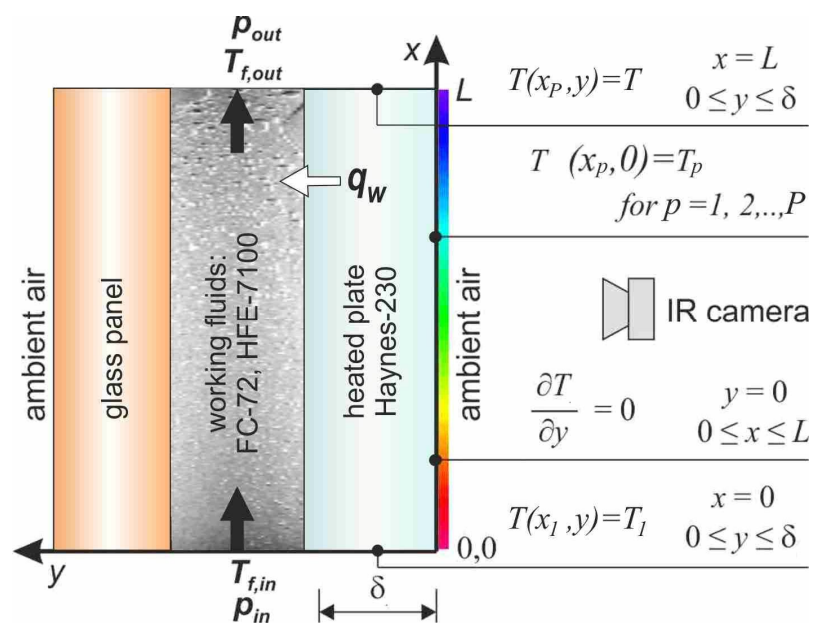

Fig. 2. Boundary conditions.

\subsection{The Beck method}

The plate temperature $T$ dependent on the boundary temperature $T_{m}$ for $m=1,2, \ldots, K$ at the boundary $y=\delta$ for $x_{1} \leq x \leq x_{P}$, like in [4], is expanded into a Taylor series around fixed point $\left(T_{01}, \ldots, T_{0 K}\right)$. Since the problem being considered is a linear problem, higher order derivatives disappear and the Taylor series has the form:

$$
T\left(x, y, T_{1}, \ldots, T_{K}\right)=\Theta(x, y)+\sum_{m=1}^{K} Z_{m}(x, y)\left(T_{m}-T_{0 m}\right)
$$

where $\Theta(x, y)=T\left(x, y, T_{01}, \ldots, T_{0 K}\right)$ and $Z_{m}(x, y)$, for $m=1,2, \ldots, K$ are the so-called sensitivity coefficients defined according to the formula:

$$
Z_{m}(x, y)=\left.\frac{\partial T}{\partial T_{m}}\right|_{T_{m}=T_{0 m}}
$$

Substituting Eq. (7) into Eq. (2) leads to $1+K$ direct problems which were solved using the Trefftz method [8].

The values of $T_{m}$ for $m=1,2, \ldots K$ in expression Eq. (7) were calculated by minimizing the following functional:

$$
J_{P}=\sum_{p=1}^{P}\left(T\left(x_{p}, y_{p}, T_{1}, \ldots, T_{K}\right)-T_{p}\right)^{2}
$$

\section{Results and discussion}

The study focused on heat transfer coefficient identification in the regions of subcooled and saturated boiling. The coefficient values were determined by solving the inverse heat conduction problem using the Beck method in combination with the Trefftz method.

a)

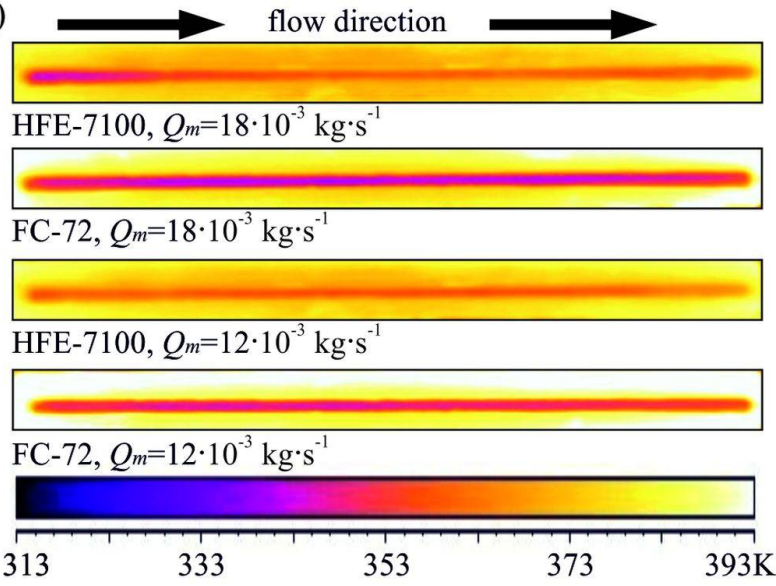

b)

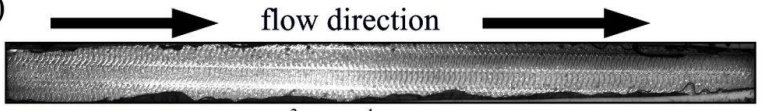

HFE-7100, $Q_{m}=18 \cdot 10^{-3} \mathrm{~kg} \cdot \mathrm{s}^{-1}$

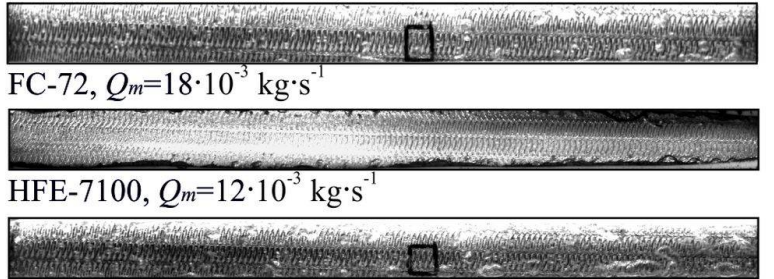

FC-72, $Q_{m}=12 \cdot 10^{-3} \mathrm{~kg} \cdot \mathrm{s}^{-1}$

Fig. 3. a) Infrared thermograms, b) two-phase flow sctuctures images, for $q_{w}=120 \mathrm{~kW} \cdot \mathrm{m}^{-2}$, two mass flow velocities, working fluids: HFE-7100 and FC-72, the saturated boiling region, experimental parameters shown in Table 1. 

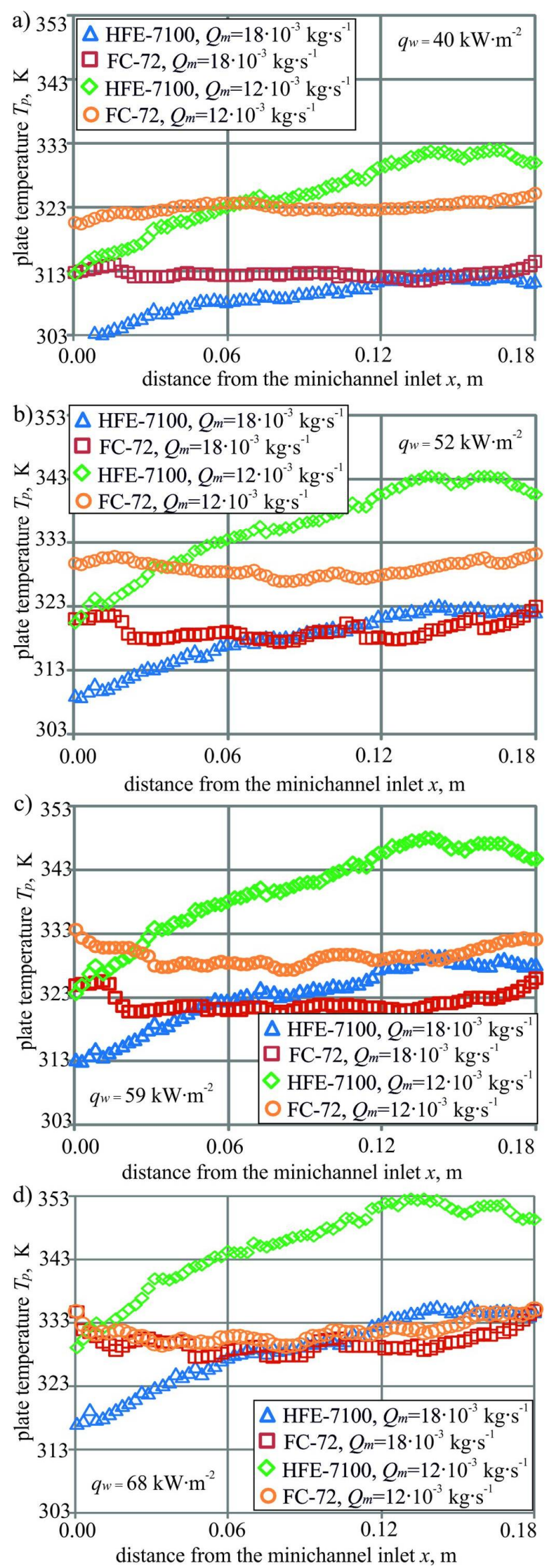

Fig. 4. Plate temperature vs. distance from the minichannel length obtained for the subcooled boiling region, experimental parameters shown in Table 1.
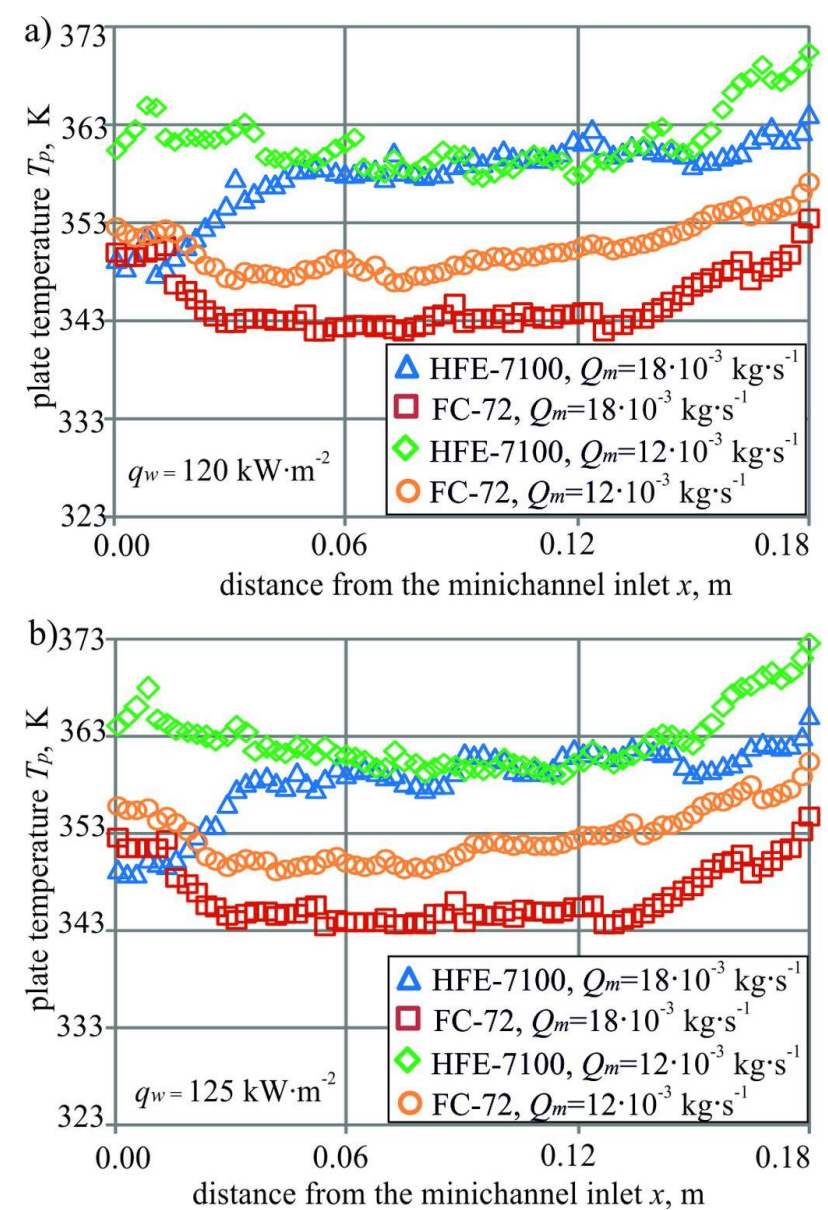

Fig. 5. Plate temperature vs. distance from the minichannel length obtained for the saturated boiling region, experimental parameters shown in Table 1.

The results are presented graphically as :

- infrared thermograms (Fig. 3a) and two-phase flow structures images (Fig. 3b), for $q_{w}=120 \mathrm{~kW} \cdot \mathrm{m}^{-2}$, two mass flow velocities, working fluids: HFE-7100 and FC-72, the saturated boiling region;

- the temperature of the outer heated plate surface determined through infrared camera measurements, for all anayzed settings of the heat flux versus the distance from the minichannel inlet, obtained for the subcooled boiling region (Fig. 4a-d) and the saturated boiling region (Fig. 5a,b);

- the heat transfer coefficient for all anayzed settings of the heat flux versus the distance from the minichannel inlet obtained for the subcooled boiling region (Fig. 6a-d) and the saturated boiling region, Fig. (7a,b).

The highest temperatures of the heated plate surface were recorded for HFE-7100 at mass flow velocity of $Q_{m}=12 \cdot 10^{-3} \mathrm{~kg} \cdot \mathrm{s}^{-1}$ in the subcooled and saturated boiling regions (except for the inlet part of the channel at subcooled boiling region). Lower temperatures were recorded for FC-72 at mass flow velocity of $Q_{m}=18 \cdot 10^{-3}$ $\mathrm{kg} \cdot \mathrm{s}^{-1}$ (except for the inlet part of the channel).

For HFE-7100, at the subcooled boiling region, the temperature rose uniformly with increasing distance from the minichannel inlet, whereas for FC-72, the temperature changes were minor. 


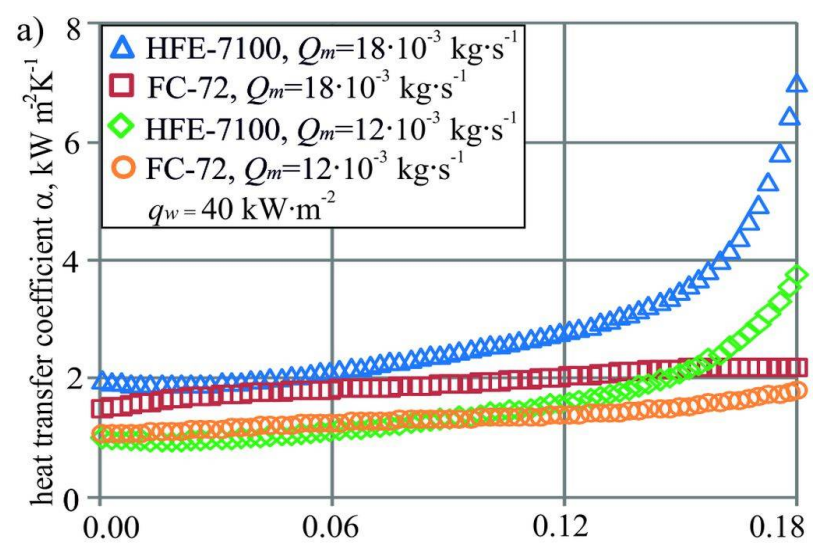

distance from the minichannel inlet $x, \mathrm{~m}$
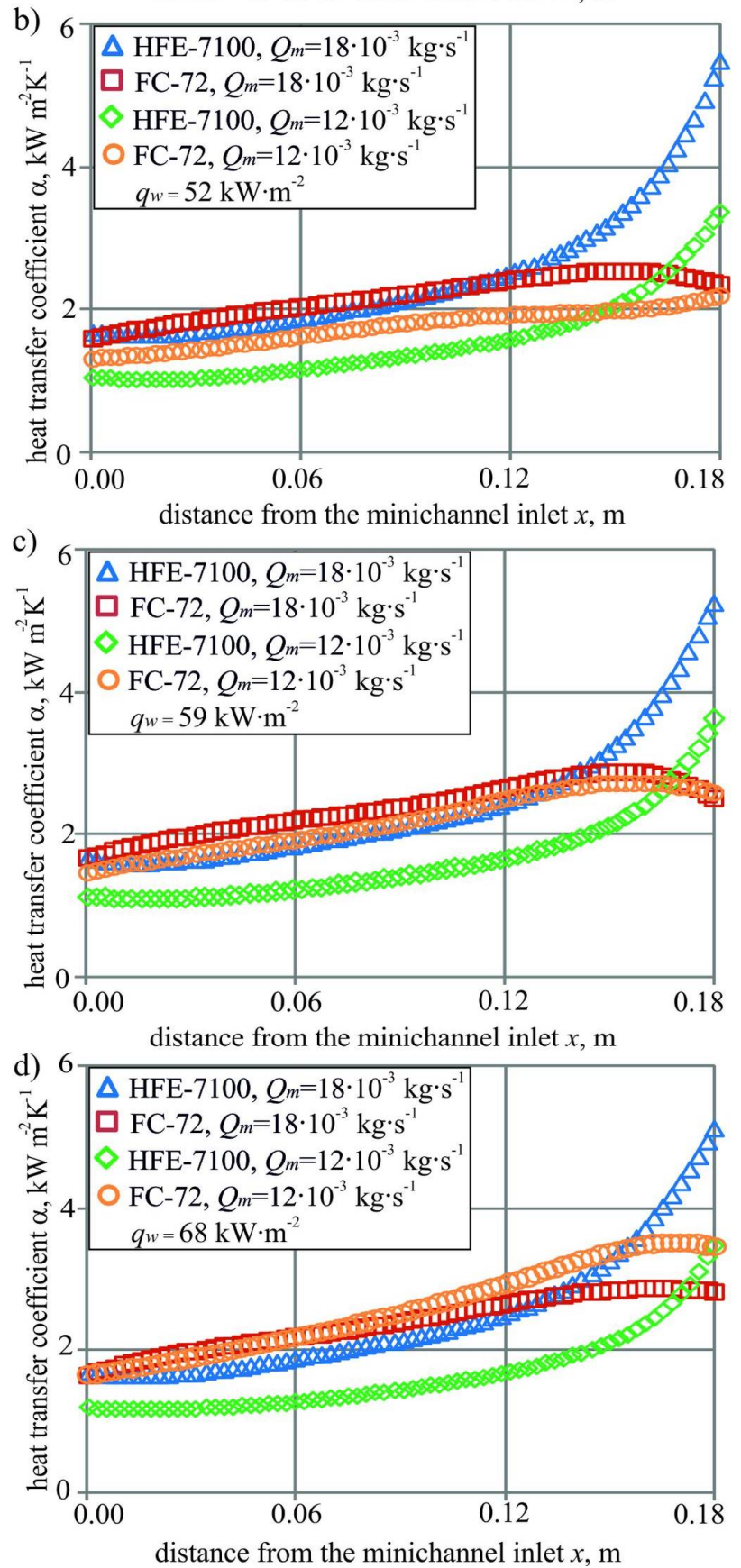

Fig. 6. Heat transfer coefficient vs. distance from the minichannel length obtained for the subcooled boiling region, experimental parameters shown in Table 1.

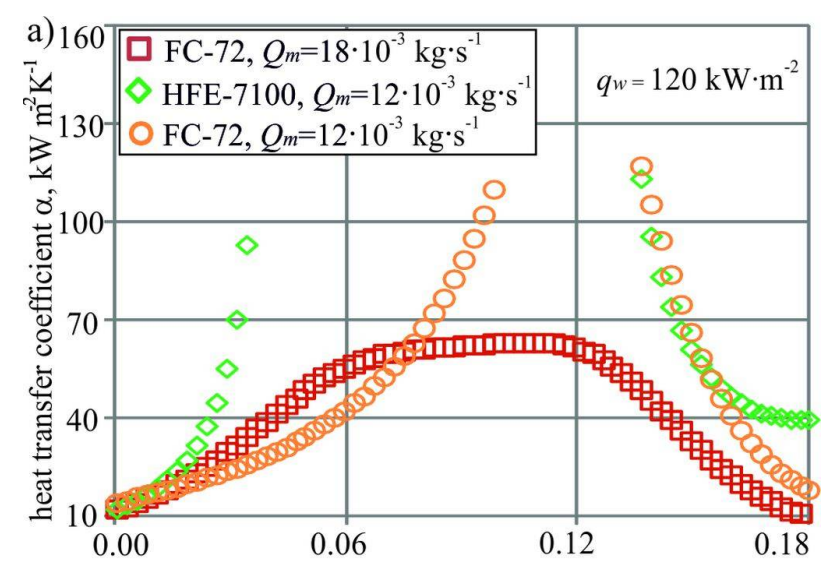

distance from the minichannel inlet $x, \mathrm{~m}$

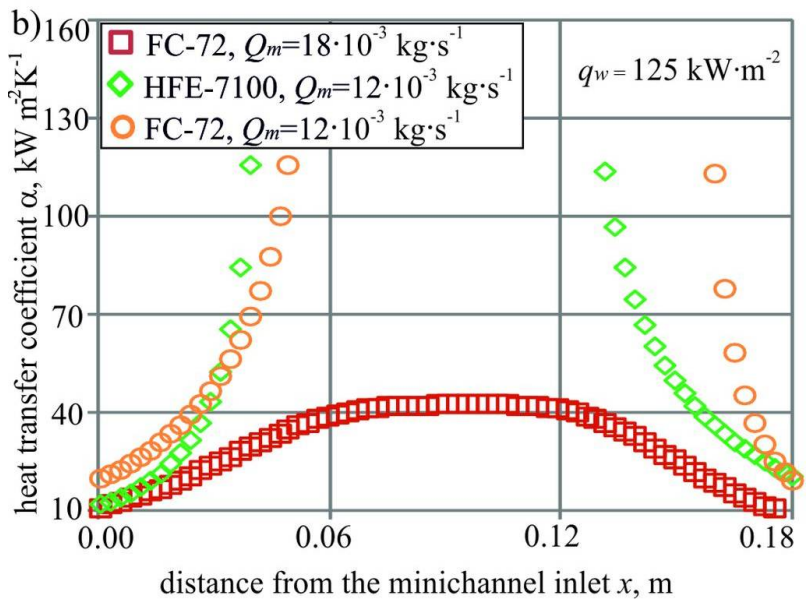

Fig. 7. Heat transfer coefficient vs. distance from the minichannel length obtained for the saturated boiling region, experimental parameters shown in Table 1.

The heated plate temperatures recorded for HFE-7100 at the saturated boiling region were higher (irrespective of the mass flow velocity) than those provided by FC-72. At this region, no substantial plate temperature increase was observed.

In the subcooled boiling region, heat transfer coefficients were in the range 1.5 to $7.0 \mathrm{~kW} \cdot \mathrm{m}^{-2} \cdot \mathrm{K}^{-1}$, that is, much lower than those obtained for the saturated boiling region. The lowest coefficients for both liquids were at the inlet to the minichannel, and the highest - at the outlet. The heat transfer coefficient calculated when HFE-7100 was used, started rising with the increasing distance from the minichannel inlet, reaching the highest values at a $2 / 3$ length of the channel from the inlet. Heat transfer coefficients obtained with HFE-7100 at mass flow velocity of $Q_{m}=18 \cdot 10^{-3} \mathrm{~kg} \cdot \mathrm{s}^{-1}$ at all the heat fluxes were recorded along the same outlet section of the minichannel. The lowest values of the heat transfer coefficient when this liquid were recorded at $Q_{m}=12 \cdot 10^{-3} \mathrm{~kg} \cdot \mathrm{s}^{-1}$ along the whole length of the channel, except for the section near the minichannel outlet. For FC-72, the coefficients had similar values in the range of $1.5-3.5 \mathrm{~kW} \cdot \mathrm{m}^{-2} \cdot \mathrm{K}^{-1}$ at both mass flow velocities. The graph of the function showed a slight coefficient drop at the very outlet of the channel. At higher heat fluxes $\left(59 \mathrm{~kW} \cdot \mathrm{m}^{-2}\right.$ and $\left.68 \mathrm{~kW} \cdot \mathrm{m}^{-2}\right), \mathrm{FC}-72$ provided higher heat transfer coefficients for both mass 
flow velocities compared to HFE-7100, except for the near-outlet section of the minichannel.

In the saturated boiling region, the heat transfer coefficient reached substantially higher values compared to the subcooled boiling region (similarly as observed in [26-28]) with the highest being from $10 \mathrm{~kW} \cdot \mathrm{m}^{-2} \mathrm{~K}^{-1}$ to $120 \mathrm{~kW} \cdot \mathrm{m}^{-2} \mathrm{~K}^{-1}$. No data were collected for HFE-7100 for $Q_{m}=18 \cdot 10^{-3} \mathrm{~kg} \cdot \mathrm{s}^{-1}$ at heat fluxes of $q_{w}=120 \mathrm{~kW} \cdot \mathrm{m}^{-2}$ and $q_{w}=125 \mathrm{~kW} \cdot \mathrm{m}^{-2}$ for both fluids for $Q_{m}=18 \cdot 10^{-3} \mathrm{~kg} \cdot \mathrm{s}^{-1}$ in the central part of the minichannel (Fig. 7a-b). It was assumed that the measurement error, $T_{p}-T_{\text {sat }}$, was about $0.5 \mathrm{~K}$, and the values $T_{p}-T_{\text {sat }}<1 \mathrm{~K}$ were not considered in the calculations. At the saturated boiling of FC-72 and at higher mass flow velocity, the heat transfer coefficient reached the lowest values of all tested liquid and mass flow velocities up to $65 \mathrm{~kW} \cdot \mathrm{m}^{-2} \cdot \mathrm{K}^{-1}$. At lower mass flow velocity for both liquids, the coefficient had much higher values (2-3 times higher) up to about $120 \mathrm{~kW} \cdot \mathrm{m}^{-2} \cdot \mathrm{K}^{-1}$. At the given mass flow velocity, heat transfer coefficients provided by HFE-7100 near the minichannel inlet were higher compared to FC-72.

\section{Conclusion}

In this work, the solution of the two-dimensional inverse heat transfer problem with the use of the Beck method coupled with the Trefftz method was proposed. The experimental data of flow boiling heat transfer in a single vertical minichannel of $1.7 \mathrm{~mm}$ depth, heated asymmetrically, were used in calculations. The heating element for two refrigerants (FC-72 and HFE-7100) flowing in the minichannel was the plate enhanced on the side contacting with the fluid. The results were presented as infrared thermographs, heated wall temperature and heat transfer coefficient as a function of the distance from the channel inlet.

The highest temperatures of the heated plate surface were recorded for HFE-7100 at mass flow velocity of $Q_{m}=12 \cdot 10^{-3} \mathrm{~kg} \cdot \mathrm{s}^{-1}$ in the subcooled and saturated boiling regions. Lower temperatures were recorded for FC-72 at mass flow velocity of $Q_{m}=18 \cdot 10^{-3} \mathrm{~kg} \cdot \mathrm{s}^{-1}$.

In the subcooled boiling region, local heat transfer coefficients were in the range 1.5 to $7.0 \mathrm{~kW} \cdot \mathrm{m}^{-2} \mathrm{~K}^{-1}$. The lowest values of the coefficients were obtained with HFE-7100 at mass flow velocity of $Q_{m}=18 \cdot 10^{-3} \mathrm{~kg} \cdot \mathrm{s}^{-1}$ at all the heat fluxes were recorded along the same outlet section of the minichannel.

In the saturated boiling region, the heat transfer coefficient reached substantially higher values compared to the subcooled boiling region, with the highest being from 10 to $120 \mathrm{~kW} \cdot \mathrm{m}^{-2} \mathrm{~K}^{-1}$. For FC-72 and at higher mass flow velocity, the heat transfer coefficient reached the lowest values of all tested refrigerants and mass flow velocities.

\section{Acknowledgments}

The research reported herein was supported by a grant from the National Science Centre, Poland (No. DEC2016/23/N/ST8/01247).

\section{References}

1. A. Tikhonov, V. Arsenin, Solution of ill-posed problems (Wiley, New York, 1977)

2. M. N. Özisịk., H. R. B. Orlande, Inverse heat transfer: fundamentals and applications. Fundamentals and Applications (Taylor \& Francis, New York, 2000)

3. J. V. Beck, B. Blackwell, C. R. St. Clair, Inverse heat conduction. Ill-posed Problems (Wiley Interscience Publ., New York, 1985)

4. B. Kruk, M Sokała, J. Appl. Math. Mech. 3, 693-694 (1999)

5. E. Trefftz, Proc. Int. Kongress für Technische Mechanik, Zürich, 131-137 (1926)

6. I. Herrera, Meth. Partial Diff. Eqs. 16, 561-580 (2000)

7. V. Kompis, F. Konkol, M. Vasko, Comp. Assis. Mech. Eng. Sci. 8, 385-395 (2001)

8. M. J. Ciałkowski, J. Therm. Sci. 11, 148-162 (2002)

9. K. Grysa, A. Maciąg, A. Pawińska, Int. J. Heat Mass Transf. 55, 7336-7340 (2012)

10. K. Grysa, B. Maciejewska, J. Theor. Appl. Mech. 51, 251-264 (2013)

11. S. Hożejowska, R. Kaniowski, M.E. Poniewski, Exp. Therm. Fluid Sci. 78, 18-29 (2016)

12. B. Maciejewska, M. Piasecka, Heat Mass Transf. 53, 1211-1224 (2017)

13. S. Blasiak, A. Pawinska, Int. J. Heat Mass Transf. 90, 710-718 (2015)

14. B. Maciejewska, M. Piasecka, Int. J. Heat Mass Transf. 107, 925-933 (2016)

15. J. R. Thome, V. Dupont, A. M. Jacobi, Int. J. Heat Mass Transf. 47, 3375-3385 (2004)

16. V. Dupont J. R. Thome, A. M. Jacobi, Int. J. Heat Mass Transf. 47, 3387-3401 (2004)

17. P. Duda, J. Taler, Int. J. Heat Mass Transf. 52, 1517-1524, (2009)

18. P. Ocłoń, S. Łopata, M. Nowak, Heat Mass Transf. 51, 553-566 (2015)

19. D. Mikielewicz, J. Wajs, M. Gliński, A.B.R.S Zrooga., Exp. Therm. Fluid Sci. 44, 556-564 (2013)

20. R.T. Lahey, D.A. Drew, Nuclear Eng. Design 204, 29-44 (2001)

21. M. Jaszczur, M Zych, R. Hanus, EPJ Web Conf. 143, paper No. 02046 (2017)

22. W. Kuczyński, H. Charun, T. Bohdal, Int. J. Heat Mass Transf. 111, 83-93 (2017)

23. Calibration certificate No. K1501035, Calibration laboratory No. 2372, accredited by Czech accreditation Institute under ČSN EN ISO/IEC 17025:2005

24. M. Piasecka, K. Strąk, B. Maciejewska, Heat Transf. Eng. 38, 332-346 (2017)

25. www.3M.cm/electronics

26. M. Piasecka, B. Maciejewska, Exp. Therm. Fluid Sci. 68, 459-467 (2015)

27. M. Piasecka, Int. J. Refrig. 56, 198-212 (2015)

28. M. Piasecka, Int. J. Heat Mass Transf. 81, 114-121 (2015) 